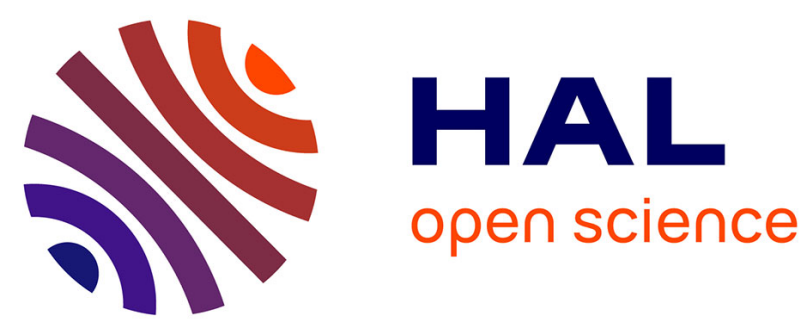

\title{
Changes in psychosocial work factors in the French working population between 2006 and 2010
}

\author{
Lucile Malard, Jean-François Chastang, Isabelle Niedhammer
}

\section{To cite this version:}

Lucile Malard, Jean-François Chastang, Isabelle Niedhammer. Changes in psychosocial work factors in the French working population between 2006 and 2010. International Archives of Occupational and Environmental Health, 2015, 88 (2), pp.235-246. 10.1007/s00420-014-0953-6 . hal-01110472

\section{HAL Id: hal-01110472 \\ https://hal.sorbonne-universite.fr/hal-01110472}

Submitted on 28 Jan 2015

HAL is a multi-disciplinary open access archive for the deposit and dissemination of scientific research documents, whether they are published or not. The documents may come from teaching and research institutions in France or abroad, or from public or private research centers.
L'archive ouverte pluridisciplinaire HAL, est destinée au dépôt et à la diffusion de documents scientifiques de niveau recherche, publiés ou non, émanant des établissements d'enseignement et de recherche français ou étrangers, des laboratoires publics ou privés. 


\section{Changes in psychosocial work factors in the French working population between 2006 and 2010}

Lucile Malard (1,2,3), Jean-François Chastang (1,2), Isabelle Niedhammer $(1,2)$

(1) INSERM, UMR_S 1136, Pierre Louis Institute of Epidemiology and Public Health, Department of social epidemiology, F-75013, Paris, France

(2) Sorbonne Universités, UPMC Univ Paris 06, UMR_S 1136, Pierre Louis Institute of Epidemiology and Public Health, Department of social epidemiology, F-75013, Paris, France

(3) Université de Versailles St-Quentin, UMR_S 1018, Villejuif, France

Correspondence to:

Dr. Isabelle Niedhammer

INSERM, UMR_S 1136, Hôpital Paul Brousse - Bâtiment 15/16

16 avenue Paul Vaillant Couturier

F-94807 Villejuif Cedex

France

Email: isabelle.niedhammer@inserm.fr

Word count: 4934 , word count of abstract: 241

5 tables, 24 references, 7 supplementary tables 


\section{Abstract}

Purpose. The aim of the study was to assess the changes in psychosocial work factors in the French working population between 2006 and 2010, and to examine potential differential changes according to age, occupation, public/private sector, work contract, and self-employed/employee status.

Methods. The study sample included 5600 workers followed up from 2006 to 2010 from the national representative SIP survey. Psychosocial work factors included decision latitude, psychological demands, social support, reward, overcommitment, long working hours, predictability, night and shift work, emotional demands, role conflict, ethical conflict, tensions with the public, job insecurity, and work-life imbalance, and were measured using scores. Linear regressions were used to analyze the change in the scores of these factors adjusted for age and initial score. All analyses were stratified by gender.

Results. Psychosocial work factors worsened between 2006 and 2010: decision latitude, social support, reward, role conflict and work-life imbalance for both genders, and psychological demands, emotional demands, ethical conflict and tensions with the public for women. Differential changes according to age, occupation, public/private sector, work contract and self-employed/employee status were observed suggesting that some groups may be more likely to be exposed to negative changes especially the younger, low and high-skilled and public sector workers.

Conclusion. Monitoring exposure to psychosocial work factors over time may be crucial, and prevention policies should take into account that deterioration of psychosocial work factors may be sharper among subgroups such as younger, low and high-skilled and public sector workers.

Key words: Changes, psychosocial work factors, France 


\section{Introduction}

Within the last decades, psychosocial work factors have become a major concern in occupational health. The deep changes that have occurred in the labour market - increased globalization, competition, flexibility, service sector and development of new forms of work organization - may have increased the prevalence of exposure to psychosocial work factors in the working population. Moreover, in 2007 in the United States, a financial crisis started due the subprime mortgage crisis, and spread all over the world. Consequently, the economic activity has slowed down. For example, in France, between 2006 and 2010, the gross domestic product (GDP) per capita decreased by $1.5 \%$, unemployment raised from $8.8 \%$ in 2006 to $9.3 \%$ in 2010, and public debt increased from $64.0 \%$ of GDP in 2006 to $79.2 \%$ of GDP in 2010. In this context of changes in the labour market and global economic crisis, the study of changes in exposures to psychosocial work factors may be a crucial topic.

Psychosocial work factors have been mainly studied as risk factors for health outcomes. Indeed, many studies showed that they were associated with a deterioration of mental health (Stansfeld and Candy 2006; Netterstrøm et al. 2008; Bonde 2008), self-reported health (Ferrie et al. 2002; Niedhammer and Chea 2003; Niedhammer et al. 2004), incidence of cardiovascular diseases (Lee et al. 2004; Kivimäki et al. 2006), etc. As psychosocial exposures at work may have adverse effects on health, it might be important to monitor the prevalence of these exposures. To our knowledge, very few studies have focused on the changes over time in the prevalence of exposure to psychosocial work factors.

The rare studies assessing the changes of psychosocial work factors over time were often limited to specific populations or sectors, to some countries or regions and to a small number of psychosocial work factors (Tsai and Chan 2011; Cheng et al. 2013; Houdmont et al. 2012; Malard et al. 2013; LaMontagne et al. 2013; Wang et al. 2010). In Taiwan, working hours, excessive work, reward, respect from superiors and colleagues, social support, and job promotion prospects improved among lawyers while "supervisor concerned about the welfare", "supervisor pays attention", interruptions and disturbances at work, and trouble sleeping at night worsened among financial workers between 2007 and 2009 according to a prospective study on 135 financial workers and lawyers (Tsai and Chan 2011). A representative Taiwanese periodical cross-sectional study showed that working more than 48 hours a week, working less than 40 hours a week, nonstandard work shift, job control, and job demands deteriorated between 2001 and 2010, and job insecurity increased in 2004 and in 2007 among 64299 Taiwanese employees (Cheng et al. 2013). In a periodical cross-sectional survey in Northern Ireland among 27037 civil servants, work stress increased between 2005 and 2010 as well as exposure to psychosocial work factors such as high job demands, low job control, low peer support, poor relationships, role ambiguity and conflict, and lack of consultation and information about change (Houdmont et al. 2012). An European periodical cross-sectional study found a degradation of decision latitude and job insecurity but an improvement of job promotion, effort, bullying, sexual harassment, long working hours, and work-life imbalance between 2005 and 2010 in a large sample of 56096 European employees (Malard et al. 2013). In Australia, job insecurity decreased from 2001 to 2007 but increased in 2008 in a prospective representative study including 13182 Australian workers (LaMontagne et al. 2013). Finally, in a cross-sectional study among 3579 Canadian employees in Alberta, job insecurity increased from the beginning of 2008 to the end of 2009 (Wang et al. 2010). 
Consequently, very few studies were performed to assess changes in psychosocial working conditions using nationally representative prospective data and a large range of psychosocial work factors. Our study is thus an attempt to fill the gap in the knowledge on the changes in psychosocial work factors over time, using prospective national representative data and a wide range of classical and emergent psychosocial work factors. This study also aimed at exploring potential differences in these changes according to age, occupation, public/private sector, work contract and self-employed/employee status.

\section{Population and methods}

Sample

The study was based on the data from the prospective and national representative SIP (Santé et Itinéraire Professionnel) survey, performed by the French Ministries of Labour and Health (DARES and DREES), the French Centre for Employment Studies (CEE) and the French National Institute for Statistics and Economic Studies (INSEE). This survey was designed to explore the complex associations between work and health (Coutrot et al. 2010). In 2006, households were randomly selected from the 1999 census, and one individual aged between 20 to 74 years was randomly selected to be interviewed. Finally, 13648 men and women from the general French population were interviewed by a trained interviewer at respondent's home. The participation rate was $76 \%$. Four years later, they were contacted again for the second wave of the survey, and 11016 individuals (81\%) participated. Among them, 2679 men and 2921 women were working in both 2006 and 2010. A study by our team has already been published using these data (Murcia et al. 2013).

Psychosocial work factors

Psychosocial work factors were measured following the classical demand-control-support (Karasek et al. 1998) and effort-reward imbalance models (Siegrist et al. 2004) and emergent concepts. No validated questionnaire was available in the SIP survey, thus proxies were constructed.

Three factors of the demand-control-support model were constructed: decision latitude (2 items: "freedom to decide how to do the work", "use of skills"), psychological demands ( 3 items: "working under pressure", "too many things to do", "excessive amount of work") and social support (1 item: "good relationships with colleagues").

Two factors of the effort-reward imbalance model were constructed: reward (1 item: "fair feedback on the work done") and overcommitment (1 item: “work still on mind when going to sleep”).

Four factors related to working time/hours were measured: long working hours ( 1 item: "working more than 48 hours a week"), predictability (1 item: "irregular hours difficult to predict"), night work (1 item: "working

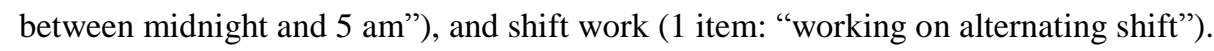

The other emergent psychosocial work factors included: emotional demands ( 1 item: "hiding feelings at work"), role conflict ( 1 item: "not being able to work following best practices"), ethical conflict ( 1 item: "exposure to unethical situations"), tensions with the public (1 item: "tensions with the public (users, students, patients, 
customers)"), job insecurity (1 item: "fear of job loss"), and work-life imbalance (1 item: "work in line with family life").

For all items, the responses were "always", "often", "sometimes" or "never" ranging from 1 to 4, the higher the value, the better the situation (if it was not the case, the value order was reversed). Thus, each psychosocial work factor had a score between 1 and 4, except decision latitude and psychological demands which were the addition of 2 and 3 items.

\section{Covariates}

The covariates were age, occupation (managers/professionals, associate professionals, clerks and manual workers), public/private sector, work contract (temporary or permanent contract) and self-employed/employee status. Occupation was coded using the French national classification of occupations that is close of the international classification (ISCO). In the analyses, age, occupation, public/private sector, work contract, and self-employed/employee status were those of 2006.

\section{Statistical analyses}

To be representative of the French working population of 2006, weights were calculated using marginal calibration and inverse probability weighting to control for the biases due to non-response in 2006 and to attrition in 2010 (De Riccardis 2012). A marginal calibration on age, work status (working/unemployed/nonworking)*age, urban area, size of household, occupation and economic activity (NAF) was performed on the sample in 2006. Homogeneous response groups were formed based on characteristics in 2006 (work status, urban area, age, level of education, gender and self-reported health), and the probability of being interviewed in 2010 was calculated for each group. Weights calculated by marginal calibration (for non-response in 2006) were multiplied by the inverse probability of being interviewed in 2010. Finally, a second marginal calibration on territorial unit, urban area, age*gender, education, nationality, and size of household was performed on the sample of individuals interviewed in 2006 and 2010 to be representative of the population of 2006. Weights were included in all statistical analyses.

Descriptive statistics were preformed to present the study sample in 2006 and 2010. To assess the changes in psychosocial work factors, the variation of score between 2006 and 2010 (score 2010 - score 2006) was calculated for each factor. A positive variation of score meant improvement in psychosocial work conditions while a negative variation meant deterioration. Regression models were used to estimate the variation of score between 2006 and 2010 adjusted for the score in 2006 and age. The mean variation of score was calculated based on these regressions as the prediction for the mean age and the distribution of the score in 2006 in the sample.

To test whether the changes were different according to covariates, regressions models were performed using the same models to which we added successively occupation, private/public sector, work contract and employee/self-employed status. Additional regression models adjusted for the score in 2006 were performed with age to test if the changes were different according to age groups. 
As psychosocial work factors differ according to gender, all analyses were performed for men and women separately.

Statistical analyses were carried out using SAS 9.3 software (SAS Institute Inc, Cary, NC).

\section{Results}

Table 1 presents the description of the study sample according to covariates in 2006 and 2010. There were few changes in the distribution of occupation, public/private sector and self-employed/employee status between 2006 and 2010, nevertheless $18 \%$ of the sample changed occupation in 2010 compared to 2006 (data not shown). Temporary contract decreased by around $50 \%$ for men and women, indeed in 2006 there were $12 \%$ and $16 \%$ of men and women with temporary contracts while in 2010 there were only $5 \%$ and $8 \%$.

Differences in the exposure to psychosocial work factors according to age, occupation, public/private sector, work contract and self-employed/employee status were observed in 2006 (Supplementary Tables S1 to S5). The prevalence of psychosocial work factors was higher among younger individuals, except for long working hours that were more prevalent among older male workers. Differences in the exposure to many factors were observed according to occupation, depending on the factor concerned, the most exposed group was either managers/professionals or manual workers. Differences in the exposure to psychosocial work factors were also found between public/private sector, temporary/permanent contract, and self-employed/employee status, but the number of significant differences was small for temporary/permanent contract.

Among men, five psychosocial work factors worsened significantly between 2006 and 2010 (Table 2). Men reported lower levels of decision latitude, social support, and reward, and higher levels of role conflict and worklife imbalance in 2010 compared to 2006. Among women, two third of the psychosocial work factors (i.e. 10 factors) showed a significant change within the period, and only one of these factors improved. In 2010 compared to 2006, women reported lower levels of decision latitude, social support, and reward, higher levels of psychological demands, emotional demands, role conflict, ethical conflict, tensions with the public, and worklife imbalance. However, women reported higher levels of predictability in 2010.

Differential changes according to age in 2006 were observed as shown in Table 3. Differences in exposure to various psychosocial work factors between age groups in 2006 were intensified between 2006 and 2010 to the detriment of younger workers for low decision latitude (men only), shift work, tensions with the public (men only), and work-life imbalance. Differential changes were also observed for factors for which there was no difference according to age in 2006 leading to differences to the detriment of younger workers for psychological demands, low social support, low predictability, and job insecurity among men, and for role conflict, ethical conflict and tensions with the public among women.

Table 4 presents the differences in changes according to occupation in 2006. The exposure to various factors was higher for low-skilled occupations (manual workers or clerks) in 2006, and the changes led to increase the gaps between occupational groups for low decision latitude, low reward (men), night work (men), shift work, and tensions with the public (men). The exposure to other factors was higher for high-skilled occupations (managers/professionals), and the changes increased the gaps between occupational groups for psychological 
demands, overcommitment, long working hours (women), emotional demands, tensions with the public (women), and work-life imbalance. For low predictability (men), role conflict (men), and tensions with the public (men), differential changes also intensified the gaps between occupations to the detriment of managers/professionals and clerks. However, differential changes in job insecurity among men reduced the difference observed in 2006 between managers/professionals and clerks.

Changes in psychosocial work factors between 2006 and 2010 were different according to public/private sector in 2006 (Table 5). Existing differences between public and private sector were exacerbated for overcommitment (women), emotional demands (women), role conflict, ethical conflict (women), and tensions with the public to the detriment of the public sector and for long working hours (men), predictability (men) and job insecurity to the detriment of the private sector. Some factors, with no public/private sector differences in 2006, displayed differential changes between 2006 and 2010 to the detriment of the public sector, these factors were decision latitude, psychological demands (women), social support (men), and reward (women).

Decision latitude and role conflict showed differential changes according work contract in 2006 among women to the detriment of temporary contract workers (Supplementary Table S6). In 2006, temporary contract women were more likely to be exposed to low decision latitude than permanent contract women, these differences were reinforced between 2006 and 2010. There was no difference in role conflict according to work status in 2006 among women, but a change in this factor was observed from 2006 to 2010 to the detriment of temporary workers.

Differential changes according to self-employed/employee were found (Supplementary Table S7). The differences in psychosocial work factors observed in 2006 to the detriment of employees were increased between 2006 and 2010 for low decision latitude, low social support (men), shift work, role conflict, and ethical conflict (women). Differences observed to the detriment of self-employed workers were also exacerbated for psychological demands (men), overcommitment (men), long working hours, low predictability, emotional demands (women), and work-life imbalance (men). Psychological demands did not differ according to selfemployed/employee status in 2006, but a change led to a gap between the two groups for this factor among women to the detriment of employees.

\section{Discussion}

A substantial number of psychosocial work factors worsened in France between 2006 and 2010 especially among women. These factors were low decision latitude, psychological demands (women), low social support, low reward and emergent factors, emotional demands (women), role conflict, ethical conflict (women), tensions with the public (women), and work-life imbalance. Differential changes according to age, occupation, public/private sector, work contract and self-employed/employee status were observed showing that some groups may be particularly exposed to negative changes, in particular young workers, high and low-skilled workers (clerks and manual workers) and public sector workers.

Few studies examined the changes in psychosocial work factors over time, and the existing literature often studied specific populations or regions based on periodical cross-sectional surveys and explored a limited number of factors, thus the comparison with our own results may be difficult. A prospective study including 135 
financial workers and lawyers in Taiwan showed that psychosocial working conditions deteriorated for financial workers while they improved for lawyers between 2007 and 2009 (Tsai and Chan 2011). As observed in our study, psychological demands increased, and social support and reward decreased between 2007 and 2009 but only for financial workers. Tsai and Chan also found an increase in overcommitment and job insecurity among financial workers. A representative periodical cross-sectional study in Taiwan among 64299 employees (Cheng et al. 2013) assessed the changes in psychosocial work factors from 2001 to 2010 and found a worsening in decision latitude, psychological demands and nonstandard work shifts which were in line with our results. They also found a deterioration in long working hours and job insecurity. In a periodical cross-sectional survey of 27037 civil servants in Northern Ireland, Houdmont et al. found a degradation of decision latitude, psychological demands, and social support (Houdmont et al. 2012), which is in agreement with our study. Using a large representative sample of 56096 employees working in 30 European countries from a cross-sectional periodical survey, in line with our results, decision latitude and skill discretion deteriorated between 2005 and 2010 (Malard et al. 2013). This study also showed opposite trends, such as an increase of job promotion (one dimension of reward) and a decrease of work-life imbalance. Other results from this European study were an increase of job insecurity, and a decrease of effort, long working hours, bullying, and sexual harassment. An 8wave prospective study in Australia found that there was a slight decrease of job insecurity from 2001 to 2007 and then a rise in 2008 among a nationally representative sample of 13182 workers (LaMontagne et al. 2013). Wang et al. found that job insecurity was higher in 2009 compared to the beginning of 2008 in a cross-sectional study among 3579 employees in Alberta, Canada (Wang et al. 2010). In our study, no worsening of job insecurity was found. Finally, a Danish study, using a split panel design of 6067, 5454 and 5404 employees representative of the labor force in 1990, 1995 and 2000, assessed the changes in job control and job insecurity between 1990 and 2000. The study period was different from ours and did not include the economic crisis of 2008 but in this period the Nordic countries were hit by an economic crisis in the early 90 's. They found an improvement in job insecurity between 1990 and 1995 and stabilization between 1995 and 2000, and there was no change in low job control (Burr et al. 2003).

The differential changes according to age, occupation, public/private sector, work contract and selfemployed/employee status have almost never been studied before. In the Taiwanese study by Cheng and al., analyses were stratified on age but no test was performed to assess whether the changes were different according to age (Cheng et al. 2013). In line with our study, they found that job control and psychological demands seemed to deteriorate more for younger and middle age workers. In the European study (Malard et al. 2013), decision latitude was more likely to deteriorate among manual workers, which is in agreement with our results. Finally, in the Australian study (LaMontagne et al. 2013), the authors found that inequalities in job control narrowed among young workers compared with older groups and for casual, fixed-term and self-employed compared with permanent workers from 2001 to 2008. They also observed a slight narrowing of disparities over time in job security between genders, age, employment arrangement and occupational skill level groups. The trends observed in the Australian study were very different compared with our results, as most of our differential changes led to increase the gaps between subgroups of the population. These discrepancies may be explained at least partly by a better economic situation of Australia over 2001-2008 compared with France over 2006-2010. 
It may be difficult to attribute these negative changes in psychosocial work factors that were found in our study to the 2008 economic crisis that occurred in the middle of the period 2006-2010. Nevertheless, these results seemed to be consistent with what may be expected in such a period of decreased economic activity with a rise in unemployment: less decision latitude, more psychological demands, less reward, more role stressors, more tensions with the public, etc. In such a difficult period, changes might have been introduced by companies such as technological and organizational changes. In additional analyses (not showed), technological and organizational changes that occurred within the study period were found to have an impact on changes in psychosocial work factors. Indeed, workers who were exposed to technological or organizational changes between 2006 and 2010 experienced a stronger deterioration of many psychosocial work factors, especially among women, compared to those who were not exposed. Thus, we may assume that technological and organizational changes might be factors that might contribute to explain the degradation of the psychosocial work environment. Competing explanations may be considered such as trends in psychosocial work factors that would have been observed even without the 2008 crisis. Only few studies explored the changes in psychosocial work factors in the period before the crisis. A French report among employees from the private sector showed a deterioration of psychological demands between 1994 and 2003 (Arnaudo et al. 2012). A Belgian study reported a deterioration in psychological demands and job insecurity but an improvement in decision latitude and social support from 1994 and 2002 (Clays et al. 2006). Comparison of the deterioration strength of psychological demands with our study was not possible, however decision latitude improved before the crisis, and deteriorated in our study, which may be in favor of an effect of the economic crisis. Moreover, in our European study, differential changes were found according to country, countries less affected by the crisis showed more positive changes than the European mean while countries more affected by the crisis showed more negative changes than the European mean (Malard et al. 2013). These differential changes may also be in favor of a potential effect of the economic crisis on psychosocial work factors. The fact that job insecurity did not worsen in our study might seem surprising as this result was found in other studies (Wang et al. 2010; Tsai and Chan 2011; Malard et al. 2013). However, this result might be explained at least in part by the fact that the rate of unemployment in France was already high in 2006 (8.8\%), and given the study design and studied sample, people were working in both 2006 and 2010, and more than $80 \%$ of them did not change of employer within the period. Consequently, our sample in 2010 may have a longer seniority and a more stable working situation (something that is confirmed by the reduction of the prevalence of temporary work contract from 2006 to 2010, in Table 1). Using a complementary sample of workers in 2010, we were able to estimate job insecurity in representative samples in 2006 and 2010 and found no differences among men and women (not showed). Therefore, even if we may assume that our study design may result in an underestimation of change in job insecurity, the additional analyses suggest that job insecurity may have not changed in France between 2006 and 2010 substantially. Reward showed the strongest deterioration for both men and women, it may be difficult to explain this result, and there has been no previous study exploring reward change. Reward may be viewed as a combination of different psychosocial work aspects (salary, job (in)security, esteem or social support, job promotion, etc.), thus it may also have been more sensitive to deterioration.

The main asset of the study was to be the first, to our knowledge, to explore the changes in psychosocial work factors over time in a nationally representative prospective sample allowing generalization to the French working population, and the assessment of the changes in a large number of psychosocial work factors and the differential 
changes according to several subgroups of the population. Indeed, only two previous studies were prospective (Tsai and Chan 2011; LaMontagne et al. 2013), and among these two studies, only one was based on a representative sample at national level (LaMontagne et al. 2013). Furthermore, the response rate to the SIP survey in 2006 was satisfactory (76\%). The results may be extrapolated to the French working population of 2006, as weights were taken into account in all statistical analyses. The analyses were powerful enough to allow stratification by gender something that may be considered fundamental (Niedhammer et al. 2000), and to observe differential changes according to several covariates. To date, only three previous studies explored the differential changes in psychosocial work factors according to age (Cheng et al. 2013), occupation (Malard et al. 2013), and gender, age, occupational skill level and employment arrangements (a combination of work contract, selfemployed status and working time) but only for job control and job security (LaMontagne et al. 2013). Moreover, a large range of psychosocial work factors were studied, both classical factors from demand-controlsupport and effort-reward models, and emergent factors such as long working hours, predictability, emotional demands, role conflict, ethical conflict, tensions with the public, job insecurity, and work-life imbalance.

Nevertheless, some limitations deserve to be mentioned. A part (19\%) of the initial sample did not participate in 2010 which might lead to a loss in statistical power and a potential selection bias. Weights were included in the analyses to reduce this potential bias. Another limitation was the floor or ceiling effect, for example a worker reporting 'never' or 'always' to one item in 2006 was not able to provide worse or better responses in 2010, even if the situation deteriorated or improved. To address this issue, statistical analyses were adjusted for baseline score of each factor. Psychosocial work factors were measured using theoretical models and emergent concepts but no validated questionnaires were available in the SIP survey leading to a potential imprecision in the measurement of the factors. However, previous studies showed the interest and validity of constructing proxies (Karasek et al. 2007). A potential selection bias should be considered, individuals in employment in 2006 but who lost their job and were not working any longer in 2010 might be a particular subgroup who might have been exposed to a stronger deterioration of their psychosocial work environment before losing their job. Consequently, this might contribute to a slight underestimation of the degradation of psychosocial work environment in our study (the number of people who become unemployed in 2010 was small, $N=277$ ). Some people also changed jobs within the study period, and part of them might have done so because of good opportunities, leading also to an underestimation of the degradation of psychosocial work factors. Finally, as the study was based on two data collections in 2006 and 2010, this prospective design might not capture all the changes in psychosocial work factors that might have occurred within the study period. For example, with only two points of data collection, our study could not be as accurate as the 8-wave Australian study and the fluctuations in job insecurity observed in this recent study may explain our non-significant results about this factor (LaMontagne et al. 2013). Psychological demands and work-life imbalance presented more missing data than other factors. Psychological demands was measured using three items, we performed additional analyses and imputed missing values by the weighted score using two items among the three items that were not missing. The results slightly changed, the deterioration was stronger for both genders, therefore, we may assume that our results may be cautious and may underestimate the actual deterioration of psychological demands. People who did not respond to the item of work-life imbalance were more likely to live alone and without children. Thus, we may assume that most of those who did not respond to the question about work-life imbalance did not feel 
concerned by the question because they had "no family". Additional analyses, considering those who did not respond to the item as non-exposed to work-life imbalance, were performed and the results were unchanged.

Additional analyses were performed to study the potential biases mentioned above. First, to study the potential bias due to attrition, the subsample of those who were interviewed in 2010 and the subsample of those who were not were compared using the data in 2006. Individuals who did not participate in 2010 were more likely to be younger, to work with a temporary contract, and non-respondent women in 2010 were more likely to work in the private sector in 2006 than women participating in 2010. Psychosocial work exposures were different between the two subsamples only among men; men who did not participate in 2010 were more likely to be exposed to low predictability, emotional demands, tensions with the public, and job insecurity. Secondly, additional analyses were performed to study the potential bias induced by workers in 2006 who lost their job during the study period. Unemployed people and workers in 2010 were compared using the data collected in 2006. Individuals who were unemployed in 2010 were more likely to be older (men), employees, and manual workers, and to have temporary contracts. They were also more likely to be exposed to low decision latitude and job insecurity, but less likely to be exposed to long working hours and tensions with the public in 2006 compared to those who were working in both 2006 and 2010. Finally, additional analyses showed that the degradation of psychosocial work factors was stronger among those who did not experience job change (change in employer, occupation, or sector/economic activity). Thus, it may be assumed that the deterioration of psychosocial work factors might be stronger if the sample was restricted to people who did not experience any job change.

To conclude, this study showed that psychosocial work factors deteriorated between 2006 and 2010 in the French working population, and that these changes were different according to age, occupation, public/private sector, work contract, and self-employed/employee status. Therefore, as psychosocial work factors are known to have an impact on health and also to play a role in social inequalities in health, monitoring exposure to psychosocial work factors over time might be crucial, and prevention policies should take into account that deterioration of psychosocial work factors might be sharper among subgroups of the population such as younger workers, low and high-skilled workers and public sector workers.

\section{Acknowledgements}

The authors thank Nicolas de Riccardis and the work group of the DREES and DARES for their help and advice with the SIP dataset.

\section{Funding}

French Ministry of Labour (DARES, Grant No 2200727156) and Université de Versailles Saint-Quentin (Lucile Malard's PhD thesis).

\section{Conflict of interest}

The authors declare that they have no conflict of interest. 


\section{References}

Arnaudo B, Léonard M, Sandret N, et al. (2012) L'évolution des risques professionnels dans le secteur privé entre 1994 et 2010 : premiers résultats de l'enquête SUMER. DARES Analyses 23:

Bonde JPE (2008) Psychosocial factors at work and risk of depression: a systematic review of the epidemiological evidence. Occup Environ Med 65:438-445. doi: 10.1136/oem.2007.038430

Burr H, Bjorner JB, Kristensen TS, et al. (2003) Trends in the Danish work environment in 1990-2000 and their associations with labor-force changes. Scand J Work Environ Health 29:270-279.

Cheng Y, Chen I-S, Burr H, et al. (2013) Changes in Psychosocial Work Conditions in Taiwanese Employees by Gender and Age from 2001 to 2010. J. Occup. Health

Clays E, De Bacquer D, Leynen F, et al. (2006) Long-term changes in the perception of job characteristics: results from the Belstress II--study. J Occup Health 48:339-346.

Coutrot T, Rouxel C, Bahu M, et al. (2010) Parcours professionnels et état de santé. Premières Informations et Premières Synthèses 1:

De Riccardis N (2012) Traitements de la non-réponse et calages pour l'enquête Santé et Itinéraire Professionnel de 2010. Document de Travail, Série Sources Méthodes 36:

Ferrie JE, Shipley MJ, Stansfeld SA, Marmot MG (2002) Effects of chronic job insecurity and change in job security on self reported health, minor psychiatric morbidity, physiological measures, and health related behaviours in British civil servants: the Whitehall II study. J Epidemiol Community Health 56:450-454.

Houdmont J, Kerr R, Addley K (2012) Psychosocial factors and economic recession: the Stormont Study. Occup Med Oxf Engl 62:98-104. doi: 10.1093/occmed/kqr216

Karasek R, Brisson C, Kawakami N, et al. (1998) The Job Content Questionnaire (JCQ): an instrument for internationally comparative assessments of psychosocial job characteristics. J Occup Health Psychol $3: 322-355$

Karasek R, Choi B, Ostergren P-O, et al. (2007) Testing two methods to create comparable scale scores between the Job Content Questionnaire (JCQ) and JCQ-like questionnaires in the European JACE Study. Int J Behav Med 14:189-201. doi: 10.1080/10705500701638336

Kivimäki M, Virtanen M, Elovainio M, et al. (2006) Work stress in the etiology of coronary heart disease--a meta-analysis. Scand J Work Environ Health 32:431-442.

LaMontagne AD, Krnjacki L, Kavanagh AM, Bentley R (2013) Psychosocial working conditions in a representative sample of working Australians 2001-2008: an analysis of changes in inequalities over time. Occup Environ Med 70:639-647. doi: 10.1136/oemed-2012-101171

Lee S, Colditz GA, Berkman LF, Kawachi I (2004) Prospective study of job insecurity and coronary heart disease in US women. Ann Epidemiol 14:24-30.

Malard L, Chastang J-F, Schütte S, et al. (2013) Changes in Psychosocial Work Exposures Among Employees Between 2005 and 2010 in 30 Countries in Europe. J Occup Environ Med Am Coll Occup Environ Med. doi: 10.1097/JOM.0b013e3182a3eb90

Murcia M, Chastang J-F, Niedhammer I (2013) Psychosocial work factors, major depressive and generalised anxiety disorders: results from the French national SIP study. J Affect Disord 146:319-327. doi: 10.1016/j.jad.2012.09.014 
Netterstrøm B, Conrad N, Bech P, et al. (2008) The relation between work-related psychosocial factors and the development of depression. Epidemiol Rev 30:118-132. doi: 10.1093/epirev/mxn004

Niedhammer I, Chea M (2003) Psychosocial factors at work and self reported health: comparative results of cross sectional and prospective analyses of the French GAZEL cohort. Occup Environ Med 60:509515.

Niedhammer I, Saurel-Cubizolles MJ, Piciotti M, Bonenfant S (2000) How is sex considered in recent epidemiological publications on occupational risks? Occup Environ Med 57:521-527.

Niedhammer I, Tek M-L, Starke D, Siegrist J (2004) Effort-reward imbalance model and self-reported health: cross-sectional and prospective findings from the GAZEL cohort. Soc Sci Med 1982 58:1531-1541. doi: 10.1016/S0277-9536(03)00346-0

Siegrist J, Starke D, Chandola T, et al. (2004) The measurement of effort-reward imbalance at work: European comparisons. Soc Sci Med 1982 58:1483-1499. doi: 10.1016/S0277-9536(03)00351-4

Stansfeld S, Candy B (2006) Psychosocial work environment and mental health--a meta-analytic review. Scand J Work Environ Health 32:443-462.

Tsai F-J, Chan C-C (2011) The impact of the 2008 financial crisis on psychological work stress among financial workers and lawyers. Int Arch Occup Environ Health 84:445-452. doi: 10.1007/s00420-010-0609-0

Wang J, Smailes E, Sareen J, et al. (2010) The prevalence of mental disorders in the working population over the period of global economic crisis. Can J Psychiatry Rev Can Psychiatr 55:598-605. 
Table 1 Description of the study sample in 2006 and 2010 according to covariates

\begin{tabular}{|c|c|c|c|c|c|c|c|c|c|}
\hline & & \multicolumn{4}{|c|}{ Men } & \multicolumn{4}{|c|}{ Women } \\
\hline & & \multicolumn{2}{|c|}{2006} & \multicolumn{2}{|c|}{2010} & \multicolumn{2}{|c|}{2006} & \multicolumn{2}{|r|}{2010} \\
\hline & & $\mathrm{N}^{\mathrm{a}}$ & $\%^{\mathrm{b}}$ & $\mathrm{N}^{\mathrm{a}}$ & $\%^{\mathrm{b}}$ & $\mathrm{N}^{\mathrm{a}}$ & $\%^{\mathrm{b}}$ & $\mathrm{N}^{\mathrm{a}}$ & $\%^{\mathrm{b}}$ \\
\hline \multirow[t]{4}{*}{ Age (years) } & {$[20 ; 30[$} & 365 & 20.5 & 167 & 9.6 & 372 & 19.8 & 182 & 9.7 \\
\hline & {$[30 ; 40[$} & 778 & 31.0 & 601 & 27.9 & 826 & 28.6 & 640 & 26.5 \\
\hline & {$[40 ; 50[$} & 916 & 31.6 & 938 & 33.1 & 1061 & 32.3 & 1012 & 31.4 \\
\hline & $50+$ & 620 & 16.9 & 973 & 29.3 & 662 & 19.3 & 1087 & 32.4 \\
\hline \multirow[t]{4}{*}{ Occupation } & Managers/professional & 458 & 17.1 & 534 & 20.1 & 379 & 11.4 & 437 & 13.2 \\
\hline & Associate professionals & 706 & 26.9 & 743 & 28.3 & 814 & 26.6 & 857 & 28.6 \\
\hline & Clerks & 536 & 22.4 & 536 & 20.3 & 1488 & 52.3 & 1432 & 50.1 \\
\hline & Manual workers & 973 & 33.5 & 865 & 31.3 & 227 & 9.8 & 195 & 8.1 \\
\hline \multirow[t]{2}{*}{ Status } & Self-employed & 296 & 10.9 & 362 & 12.7 & 214 & 7.3 & 233 & 7.7 \\
\hline & Employees & 2334 & 89.1 & 2317 & 87.4 & 2628 & 92.8 & 2688 & 92.3 \\
\hline \multirow[t]{2}{*}{ Sector } & Public & 503 & 18.6 & 485 & 18.1 & 956 & 30.0 & 968 & 30.2 \\
\hline & Private & 2127 & 81.4 & 2194 & 81.9 & 1886 & 70.0 & 1953 & 69.8 \\
\hline \multirow[t]{2}{*}{ Work contract } & Temporary & 286 & 12.0 & 111 & 5.1 & 407 & 16.3 & 212 & 8.3 \\
\hline & Permanent & 2317 & 88.0 & 2463 & 94.9 & 2442 & 83.7 & 2660 & 91.7 \\
\hline
\end{tabular}

\footnotetext{
${ }^{a}$ Non-weighted number of individuals

${ }^{\mathrm{b}}$ Weighted frequency distribution
} 
Table 2 Mean changes in psychosocial work factors: results from linear regression models adjusted for age in 2006 and score of factor in 2006

\begin{tabular}{|c|c|c|c|c|c|c|c|c|c|c|}
\hline & \multicolumn{5}{|c|}{ Men } & \multicolumn{5}{|c|}{ Women } \\
\hline & $\mathrm{N}$ & $\begin{array}{c}\text { Mean score } \\
2006^{\mathrm{a}} \\
\end{array}$ & Mean change ${ }^{b}$ & $95 \% \mathrm{CI}$ & $\mathrm{p}$ & $\mathrm{N}$ & $\begin{array}{c}\text { Mean score } \\
2006^{\mathrm{a}} \\
\end{array}$ & Mean change ${ }^{b}$ & $95 \% \mathrm{CI}$ & $\mathrm{p}$ \\
\hline Low decision latitude & 2583 & 6.77 & -0.06 & {$[-0.12 ; 0.00]$} & $*$ & 2776 & 6.80 & -0.06 & {$[-0.12 ; 0.00]$} & $*$ \\
\hline Psychological demands & 2309 & 8.61 & -0.09 & {$[-0.19 ; 0.01]$} & ns & 2567 & 8.91 & -0.28 & {$[-0.38 ;-0.18]$} & $* * *$ \\
\hline Low social support & 2630 & 3.68 & -0.08 & {$[-0.11 ;-0.05]$} & $* * *$ & 2841 & 3.69 & -0.07 & {$[-0.10 ;-0.05]$} & $* * *$ \\
\hline Low reward & 2630 & 2.93 & -0.31 & {$[-0.35 ;-0.26]$} & $* * *$ & 2841 & 2.92 & -0.25 & {$[-0.29 ;-0.21]$} & $* * *$ \\
\hline Overcommitment & 2583 & 2.95 & -0.01 & {$[-0.05 ; 0.03]$} & ns & 2776 & 2.92 & 0.00 & {$[-0.04 ; 0.04]$} & ns \\
\hline Long working hours & 2583 & 3.21 & 0.01 & {$[-0.03 ; 0.05]$} & ns & 2776 & 3.63 & -0.02 & {$[-0.05 ; 0.02]$} & $\mathrm{ns}$ \\
\hline Low predictability & 2583 & 3.37 & -0.02 & {$[-0.06 ; 0.02]$} & ns & 2776 & 3.58 & 0.05 & {$[0.02 ; 0.08]$} & $* *$ \\
\hline Night work & 2630 & 3.54 & 0.01 & {$[-0.03 ; 0.04]$} & ns & 2842 & 3.80 & -0.01 & {$[-0.03 ; 0.02]$} & $\mathrm{ns}$ \\
\hline Shift work & 2583 & 3.53 & 0.00 & {$[-0.03 ; 0.04]$} & ns & 2776 & 3.59 & -0.01 & {$[-0.04 ; 0.03]$} & ns \\
\hline Emotional demands & 2583 & 2.90 & -0.03 & {$[-0.08 ; 0.02]$} & ns & 2776 & 2.54 & -0.12 & {$[-0.17 ;-0.08]$} & $* * *$ \\
\hline Role conflict & 2583 & 3.35 & -0.06 & {$[-0.10 ;-0.03]$} & $* * *$ & 2776 & 3.33 & -0.11 & {$[-0.14 ;-0.07]$} & $* * *$ \\
\hline Ethical conflict & 2583 & 3.56 & -0.02 & {$[-0.04 ; 0.01]$} & $\mathrm{ns}$ & 2776 & 3.62 & -0.06 & {$[-0.09 ;-0.04]$} & $* * *$ \\
\hline Tensions with the public & 2630 & 3.45 & -0.03 & {$[-0.06 ; 0.00]$} & ns & 2841 & 3.38 & -0.06 & {$[-0.09 ;-0.03]$} & $* * *$ \\
\hline Job insecurity & 2583 & 3.65 & 0.03 & {$[0.00 ; 0.06]$} & ns & 2776 & 3.67 & 0.02 & {$[0.00 ; 0.05]$} & ns \\
\hline Work-life imbalance & 2169 & 3.45 & -0.10 & {$[-0.14 ;-0.07]$} & $* * *$ & 2369 & 3.50 & -0.06 & {$[-0.10 ;-0.03]$} & $* * *$ \\
\hline
\end{tabular}

${ }^{\mathrm{a}}$ The lower the score, the higher the exposure

${ }^{\mathrm{b}}$ Mean change: mean of the variation (score 2010 - score 2006), a negative mean change meant a deterioration of the factor between 2006 and 2010

$* \mathrm{p}<0.05 ; * * \mathrm{p}<0.01 ; * * * \mathrm{p}<0.001$ 
Table 3 Differential changes according to age in 2006: results from linear regression models adjusted for score of factor in 2006

\begin{tabular}{|c|c|c|c|c|c|c|c|c|c|c|c|c|}
\hline & \multicolumn{3}{|c|}{$20-30$ y } & \multicolumn{3}{|c|}{$30-40$ y } & \multicolumn{3}{|c|}{$40-50 y$} & \multirow{2}{*}{$\begin{array}{c}+50 \mathrm{y} \\
\text { (ref.) }\end{array}$} & \multirow[t]{2}{*}{$\mathrm{p}^{\mathrm{c}}$} & \multirow[t]{2}{*}{$\mathrm{p}^{\mathrm{d}}$} \\
\hline & $\begin{array}{l}\text { Mean score } \\
2006^{\mathrm{a}}\end{array}$ & Beta $^{b}$ & $95 \% \mathrm{CI}$ & $\begin{array}{l}\text { Mean } \\
\text { score } \\
2006^{\text {a }}\end{array}$ & Beta $^{b}$ & $95 \% \mathrm{CI}$ & $\begin{array}{l}\text { Mean } \\
\text { score } \\
2006^{\text {a }}\end{array}$ & Beta $^{b}$ & $95 \% \mathrm{CI}$ & & & \\
\hline \multicolumn{13}{|l|}{ Men } \\
\hline Low decision latitude & 6.45 & $-0.41 * * *$ & {$[-0.61 ;-0.20]$} & 6.80 & $-0.19 *$ & {$[-0.35 ;-0.04]$} & 6.86 & $-0.23 * *$ & {$[-0.37 ;-0.08]$} & 6.87 & $* *$ & $* * *$ \\
\hline Psychological demands & 8.62 & $-0.68 * * *$ & {$[-1.04 ;-0.31]$} & 8.54 & $-0.49 * * *$ & {$[-0.77 ;-0.21]$} & 8.61 & $-0.29 *$ & {$[-0.56 ;-0.02]$} & 8.73 & $\mathrm{~ns}$ & $* * *$ \\
\hline Low social support & 3.69 & -0.08 & {$[-0.17 ; 0.00]$} & 3.65 & $-0.16 * * *$ & {$[-0.23 ;-0.09]$} & 3.69 & $-0.12 * * *$ & {$[-0.19 ;-0.05]$} & 3.70 & ns & $* * *$ \\
\hline Low predictability & 3.28 & $-0.27 * * *$ & {$[-0.41 ;-0.12]$} & 3.35 & $-0.11 *$ & {$[-0.21 ;-0.01]$} & 3.40 & $-0.11 *$ & {$[-0.21 ;-0.01]$} & 3.47 & ns & $* *$ \\
\hline Shift work & 3.39 & -0.12 & {$[-0.26 ; 0.01]$} & 3.48 & $-0.17 * * *$ & {$[-0.27 ;-0.07]$} & 3.55 & $-0.11 *$ & {$[-0.19 ;-0.03]$} & 3.74 & $* * *$ & $* *$ \\
\hline Tensions with the public & 3.44 & $-0.15 * *$ & {$[-0.25 ;-0.04]$} & 3.38 & -0.05 & {$[-0.13 ; 0.04]$} & 3.46 & -0.01 & {$[-0.09 ; 0.07]$} & 3.56 & $* *$ & $*$ \\
\hline Job insecurity & 3.62 & $-0.20 * * *$ & {$[-0.30 ;-0.09]$} & 3.64 & $-0.17 * * *$ & {$[-0.24 ;-0.09]$} & 3.66 & $-0.12 * * *$ & {$[-0.18 ;-0.05]$} & 3.68 & ns & $* * *$ \\
\hline Work-life imbalance & 3.40 & $-0.18 * *$ & {$[-0.32 ;-0.04]$} & 3.39 & $-0.14 *$ & {$[-0.24 ;-0.03]$} & 3.46 & 0.00 & {$[-0.10 ; 0.10]$} & 3.56 & $*$ & $* *$ \\
\hline \multicolumn{13}{|l|}{ Women } \\
\hline Shift work & 3.31 & $-0.18 * *$ & {$[-0.31 ;-0.06]$} & 3.59 & -0.05 & {$[-0.13 ; 0.03]$} & 3.67 & 0.00 & {$[-0.07 ; 0.07]$} & 3.72 & $* * *$ & $*$ \\
\hline Role conflict & 3.33 & $-0.18 * *$ & {$[-0.30 ;-0.05]$} & 3.32 & -0.09 & {$[-0.19 ; 0.00]$} & 3.31 & $-0.09 *$ & {$[-0.17 ; 0.00]$} & 3.39 & $\mathrm{~ns}$ & $*$ \\
\hline Ethical conflict & 3.52 & $-0.17 * * *$ & {$[-0.27 ;-0.07]$} & 3.65 & $-0.12 * *$ & {$[-0.19 ;-0.05]$} & 3.64 & -0.05 & {$[-0.11 ; 0.02]$} & 3.65 & $\mathrm{~ns}$ & $* * *$ \\
\hline Tensions with the public & 3.28 & $-0.23 * * *$ & {$[-0.34 ;-0.12]$} & 3.38 & $-0.12 * *$ & {$[-0.21 ;-0.04]$} & 3.42 & -0.05 & {$[-0.13 ; 0.02]$} & 3.43 & ns & $* * *$ \\
\hline Work-life imbalance & 3.42 & $-0.20 * *$ & {$[-0.33 ;-0.06]$} & 3.39 & $-0.14 * *$ & {$[-0.24 ;-0.04]$} & 3.53 & -0.06 & {$[-0.15 ; 0.03]$} & 3.66 & $* * *$ & $* *$ \\
\hline
\end{tabular}


Table 4 Differential changes according to occupation in 2006: results from linear regression models adjusted for age in 2006 and score of factor in 2006

\begin{tabular}{|c|c|c|c|c|c|c|c|c|c|c|c|c|}
\hline & \multicolumn{3}{|c|}{ Managers/professionals } & \multicolumn{3}{|c|}{ Associate professionals } & \multicolumn{3}{|c|}{ Clerks } & \multirow{2}{*}{$\begin{array}{c}\begin{array}{c}\text { Manual workers } \\
\text { (ref.) }\end{array} \\
\text { Mean score } \\
2006^{\mathrm{a}} \\
\end{array}$} & \multirow[t]{2}{*}{$\mathrm{p}^{\mathrm{c}}$} & \multirow[t]{2}{*}{$\mathrm{p}^{\mathrm{d}}$} \\
\hline & $\begin{array}{l}\text { Mean } \\
\text { score } \\
2006^{\mathrm{a}}\end{array}$ & Beta $^{b}$ & $95 \% \mathrm{CI}$ & $\begin{array}{l}\text { Mean } \\
\text { score } \\
2006^{a}\end{array}$ & Beta $^{\mathrm{b}}$ & $95 \% \mathrm{CI}$ & $\begin{array}{l}\text { Mean } \\
\text { score } \\
2006^{\mathrm{a}}\end{array}$ & Beta $^{b}$ & $95 \% \mathrm{CI}$ & & & \\
\hline \multicolumn{13}{|l|}{ Men } \\
\hline Low decision latitude & 7.20 & $0.28 * *$ & {$[0.11 ; 0.44]$} & 6.86 & $0.22 * *$ & {$[0.07 ; 0.38]$} & 6.66 & 0.02 & {$[-0.16 ; 0.19]$} & 6.54 & $* * *$ & $* *$ \\
\hline Psychological demands & 7.80 & $-0.39 *$ & {$[-0.69 ;-0.09]$} & 8.11 & $-0.38 * *$ & {$[-0.65 ;-0.12]$} & 8.80 & -0.27 & {$[-0.58 ; 0.04]$} & 9.29 & $* * *$ & $*$ \\
\hline Low reward & 3.14 & $0.26^{* * *}$ & {$[0.14 ; 0.39]$} & 2.92 & 0.09 & {$[-0.02 ; 0.21]$} & 2.80 & -0.06 & {$[-0.19 ; 0.08]$} & 2.92 & $* * *$ & $* * *$ \\
\hline Overcommitment & 2.61 & $-0.22 * * *$ & {$[-0.34 ;-0.10]$} & 2.83 & $-0.20 * * *$ & {$[-0.30 ;-0.10]$} & 2.96 & $-0.17 * *$ & {$[-0.29 ;-0.05]$} & 3.23 & $* * *$ & $* * *$ \\
\hline Long working hours & 2.90 & $-0.17 * *$ & {$[-0.29 ;-0.05]$} & 3.25 & -0.05 & {$[-0.15 ; 0.06]$} & 2.92 & $-0.10 *$ & {$[-0.21 ; 0.00]$} & 3.52 & $* * *$ & $*$ \\
\hline Low predictability & 3.30 & $-0.12 *$ & {$[-0.24 ;-0.01]$} & 3.41 & $-0.13^{*}$ & {$[-0.23 ;-0.03]$} & 3.27 & $-0.19 * *$ & {$[-0.31 ;-0.07]$} & 3.46 & $*$ & $* *$ \\
\hline Night work & 3.81 & $0.19 * * *$ & {$[0.11 ; 0.28]$} & 3.70 & $0.14 * *$ & {$[0.05 ; 0.23]$} & 3.39 & -0.02 & {$[-0.13 ; 0.09]$} & 3.39 & $* * *$ & $* * *$ \\
\hline Shift work & 3.93 & $0.33 * * *$ & {$[0.25 ; 0.42]$} & 3.68 & $0.22 * * *$ & {$[0.12 ; 0.32]$} & 3.39 & $0.18^{* * *}$ & {$[0.05 ; 0.31]$} & 3.30 & $* * *$ & $* * *$ \\
\hline Emotional demands & 2.59 & $-0.30 * * *$ & {$[-0.43 ;-0.16]$} & 2.78 & $-0.13^{*}$ & {$[-0.25 ;-0.02]$} & 2.69 & $-0.23 * *$ & {$[-0.37 ;-0.09]$} & 3.31 & $* * *$ & $* * *$ \\
\hline Role conflict & 3.36 & $-0.11^{*}$ & {$[-0.21 ;-0.01]$} & 3.27 & -0.08 & {$[-0.16 ; 0.01]$} & 3.36 & $-0.15 * *$ & {$[-0.25 ;-0.05]$} & 3.41 & $*$ & $*$ \\
\hline Tensions with the public & 3.28 & $-0.16 * *$ & {$[-0.26 ;-0.06]$} & 3.39 & $-0.18 * * *$ & {$[-0.26 ;-0.10]$} & 3.27 & $-0.18 * * *$ & {$[-0.27 ;-0.09]$} & 3.70 & $* * *$ & $* * *$ \\
\hline Job insecurity & 3.67 & $0.08 *$ & {$[0.01 ; 0.16]$} & 3.65 & 0.02 & {$[-0.05 ; 0.10]$} & 3.73 & -0.08 & {$[-0.18 ; 0.03]$} & 3.57 & $* *$ & $*$ \\
\hline Low decision latitude & 7.02 & $0.38 * *$ & {$[0.09 ; 0.67]$} & 6.97 & 0.17 & {$[-0.10 ; 0.45]$} & 6.79 & 0.14 & {$[-0.13 ; 0.41]$} & 6.10 & $* * *$ & $* *$ \\
\hline Psychological demands & 7.93 & $-1.06^{* * * *}$ & {$[-1.59 ;-0.53]$} & 8.32 & $-0.94 * * *$ & {$[-1.43 ;-0.46]$} & 9.38 & $-0.55^{*}$ & {$[-1.02 ;-0.09]$} & 9.16 & $* * *$ & $* * *$ \\
\hline Overcommitment & 2.47 & $-0.34 * * *$ & {$[-0.54 ;-0.15]$} & 2.68 & $-0.24 *$ & {$[-0.42 ;-0.05]$} & 3.10 & -0.15 & {$[-0.33 ; 0.02]$} & 3.14 & $* * *$ & $* *$ \\
\hline Long working hours & 3.25 & $-0.24 * * *$ & {$[-0.38 ;-0.11]$} & 3.61 & $-0.19 * * *$ & {$[-0.30 ;-0.09]$} & 3.70 & -0.08 & {$[-0.17 ; 0.01]$} & 3.78 & $* * *$ & $* * *$ \\
\hline Shift work & 3.96 & $0.31^{* * * *}$ & {$[0.15 ; 0.48]$} & 3.55 & $0.22 *$ & {$[0.04 ; 0.40]$} & 3.61 & 0.15 & {$[-0.03 ; 0.33]$} & 3.13 & $* * *$ & $* * *$ \\
\hline Emotional demands & 2.30 & $-0.32 * *$ & {$[-0.54 ;-0.11]$} & 2.36 & $-0.35^{* * *}$ & {$[-0.56 ;-0.15]$} & 2.59 & $-0.27 * *$ & {$[-0.46 ;-0.08]$} & 3.05 & $* * *$ & $* *$ \\
\hline Tensions with the public & 3.30 & $-0.29 * * *$ & {$[-0.41 ;-0.16]$} & 3.17 & $-0.30 * * *$ & {$[-0.42 ;-0.18]$} & 3.43 & $-0.23 * * *$ & {$[-0.34 ;-0.13]$} & 3.80 & $* * *$ & $* * *$ \\
\hline Work-life imbalance & 3.23 & $-0.23 *$ & {$[-0.41 ;-0.05]$} & 3.40 & -0.08 & {$[-0.23 ; 0.08]$} & 3.59 & 0.00 & {$[-0.15 ; 0.14]$} & 3.59 & $* * *$ & $* *$ \\
\hline
\end{tabular}


${ }^{a}$ Mean score in 2006 according to occupation group, the lower the score, the higher the exposure

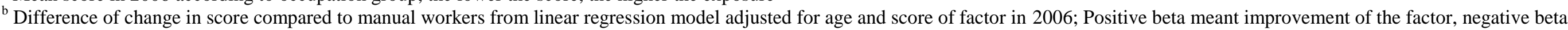
deterioration of the factor compared to reference group

${ }^{c}$ Global p-value for differences in score in 2006 according to occupation

${ }^{\mathrm{d}}$ Global p-value for differences in change in score between 2006 and 2010 according to occupation

$* \mathrm{p}<0.05 ; * * \mathrm{p}<0.01 ; * * * \mathrm{p}<0.001$

Only the factors showing significant changes according to occupation are presented 
Table 5 Differential changes according to public/private sector in 2006: results from linear regression models adjusted for age in 2006 and score of factor in 2006

\begin{tabular}{|c|c|c|c|c|c|c|}
\hline & \multicolumn{3}{|c|}{ Public } & \multirow{2}{*}{$\frac{\text { Private (ref.) }}{\text { Mean score } 2006^{\mathrm{a}}}$} & \multirow[t]{2}{*}{$\mathrm{p}^{\mathrm{c}}$} & \multirow[t]{2}{*}{$p^{d}$} \\
\hline & Mean score $2006^{a}$ & Beta $^{b}$ & $95 \% \mathrm{CI}$ & & & \\
\hline \multicolumn{7}{|l|}{ Men } \\
\hline Low decision latitude & 6.76 & $-0.28 * * *$ & {$[-0.43 ;-0.12]$} & 6.77 & $\mathrm{~ns}$ & $* * *$ \\
\hline Low social support & 3.66 & $-0.10^{* *}$ & {$[-0.18 ;-0.03]$} & 3.68 & ns & $* *$ \\
\hline Long working hours & 3.48 & $0.16^{* * * *}$ & {$[0.08 ; 0.24]$} & 3.14 & $* * *$ & $* * *$ \\
\hline Low predictability & 3.47 & $0.12 * *$ & {$[0.03 ; 0.21]$} & 3.35 & $*$ & $* *$ \\
\hline Role conflict & 3.21 & $-0.26^{* * * *}$ & {$[-0.34 ;-0.17]$} & 3.38 & $* * *$ & $* * *$ \\
\hline Tensions with the public & 3.22 & $-0.20 * * *$ & {$[-0.28 ;-0.11]$} & 3.50 & $* * *$ & $* * *$ \\
\hline Job insecurity & 3.87 & $0.16^{* * * *}$ & {$[0.10 ; 0.21]$} & 3.59 & $* * *$ & $* * *$ \\
\hline \multicolumn{7}{|l|}{ Women } \\
\hline Low decision latitude & 6.80 & $-0.13 *$ & {$[-0.25 ;-0.01]$} & 6.80 & $\mathrm{~ns}$ & $*$ \\
\hline Psychological demands & 8.75 & $-0.50 * * *$ & {$[-0.71 ;-0.29]$} & 8.98 & $\mathrm{~ns}$ & $* * *$ \\
\hline Low reward & 2.86 & $-0.13^{* *}$ & {$[-0.22 ;-0.05]$} & 2.95 & $\mathrm{~ns}$ & $* *$ \\
\hline Overcommitment & 2.83 & $-0.16^{* * * *}$ & {$[-0.24 ;-0.07]$} & 2.96 & $* *$ & $* * *$ \\
\hline Emotional demands & 2.43 & $-0.14 * *$ & {$[-0.24 ;-0.05]$} & 2.59 & $* *$ & $* *$ \\
\hline Role conflict & 3.19 & $-0.14^{* * * *}$ & {$[-0.21 ;-0.06]$} & 3.40 & $* * *$ & $* * *$ \\
\hline Ethical conflict & 3.57 & $-0.08 * *$ & {$[-0.14 ;-0.02]$} & 3.64 & $*$ & $* *$ \\
\hline Tensions with the public & 3.22 & $-0.19 * * *$ & {$[-0.26 ;-0.12]$} & 3.45 & $* * *$ & $* * *$ \\
\hline Job insecurity & 3.83 & $0.16 * * *$ & {$[0.11 ; 0.21]$} & 3.60 & $* * *$ & $* * *$ \\
\hline
\end{tabular}

a Mean score in 2006 according to public/private sector, the lower the score, the higher the exposure

$\mathrm{b}$ Difference of change in score compared to private sector from linear regression model adjusted for age and score of factor in 2006; Positive beta meant improvement of the factor, negative beta deterioration of the factor compared to reference group

c Global p-value for differences in score in 2006 according to public/private sector

$\mathrm{d}$ Global p-value for differences in change in score between 2006 and 2010 according to public/private sector $* \mathrm{p}<0.05 ; * * \mathrm{p}<0.01 ; * * * \mathrm{p}<0.001$

Only the factors with significant differences according to public/private sector are presented 